Supporting Information for:

\title{
Hindered Translator and Hindered Rotor Models for Adsorbates: Partition Functions and Entropies
}

\author{
Lynza H. Sprowl, Charles T. Campbell, and Líney Árnadóttir*
}

Table S1. Binding energies, in $\mathrm{eV}$, of the initial state, translational transition state, and rotational transition state on a $\mathrm{Pt}(111)$ surface.

\begin{tabular}{|c|c|c|c|c|c|c|c|c|c|c|}
\hline & \multicolumn{2}{|c|}{ Methanol } & \multicolumn{2}{c|}{ Propane $\left(\mathrm{C}_{2}\right)$} & \multicolumn{2}{c|}{ Propane $\left(\mathrm{C}_{1}\right)$} & \multicolumn{2}{c|}{ Ethane } & \multicolumn{2}{c|}{ Methane } \\
\hline vdW included & yes & no & yes & no & yes & no & yes & no & yes & no \\
\hline Initial State & -0.73 & -0.31 & -0.66 & -0.06 & -0.64 & -0.05 & -0.46 & -0.05 & -0.27 & -0.04 \\
\hline Trans TS & -0.43 & -0.09 & -0.56 & -0.02 & -0.57 & -0.03 & -0.41 & -0.03 & -0.26 & -0.03 \\
\hline Rot TS & -0.73 & -0.30 & -0.64 & -0.06 & -0.59 & -0.03 & -0.44 & -0.04 & -0.27 & -0.04 \\
\hline
\end{tabular}

Table S2. Distances, in Angstroms, between $\mathrm{O}$ and $\mathrm{C}$ atoms and the Pt surface for the initial state, translational transition state, and rotational transition state configurations. Propane $\left(\mathrm{C}_{2}\right)$ has its central $\left(\mathrm{C}_{2}\right)$ carbon atom closest to the surface, while propane $\left(\mathrm{C}_{1}\right)$ has its terminal $\left(\mathrm{C}_{1}\right)$ carbon atoms closer to the surface.

\begin{tabular}{|c|c|c|c|c|c|c|c|c|c|c|c|}
\hline \multirow{2}{*}{\multicolumn{2}{|c|}{ vdW included }} & \multicolumn{2}{|c|}{ Methanol } & \multicolumn{2}{|c|}{ Propane $\left(\mathrm{C}_{2}\right)$} & \multicolumn{2}{|c|}{ Propane $\left(\mathrm{C}_{1}\right)$} & \multicolumn{2}{|c|}{ Ethane } & \multicolumn{2}{|c|}{ Methane } \\
\hline & & yes & no & yes & no & yes & no & yes & no & yes & no \\
\hline \multirow{4}{*}{$\begin{array}{l}\text { Initial } \\
\text { State }\end{array}$} & $\mathrm{O}$ & 2.24 & 2.29 & & & & & & & & \\
\hline & $\mathrm{C} 1$ & 3.03 & 3.13 & 3.35 & 3.87 & 3.23 & 3.60 & 3.19 & 3.52 & 3.32 & 3.80 \\
\hline & $\mathrm{C} 2$ & & & 3.13 & 3.35 & 3.36 & 3.88 & 3.36 & 4.06 & & \\
\hline & $\mathrm{C} 3$ & & & 3.33 & 3.88 & 3.30 & 3.65 & & & & \\
\hline \multirow{4}{*}{$\begin{array}{c}\text { Trans } \\
\text { TS }\end{array}$} & $\mathrm{O}$ & 2.76 & 2.87 & & & & & & & & \\
\hline & $\mathrm{C} 1$ & 3.42 & 3.67 & 3.45 & 4.00 & 3.36 & 3.70 & 3.35 & 3.64 & 3.38 & 3.86 \\
\hline & $\mathrm{C} 2$ & & & 3.24 & 3.52 & 3.48 & 4.00 & 3.50 & 4.21 & & \\
\hline & $\mathrm{C} 3$ & & & 3.55 & 4.06 & 3.43 & 3.84 & & & & \\
\hline \multirow{4}{*}{$\begin{array}{l}\text { Rot } \\
\text { TS }\end{array}$} & $\mathrm{O}$ & 2.26 & 2.29 & & & & & & & & \\
\hline & $\mathrm{C} 1$ & 3.05 & 3.13 & 3.35 & 3.87 & 3.24 & 3.60 & 3.20 & 3.52 & 3.32 & 3.80 \\
\hline & $\mathrm{C} 2$ & & & 3.13 & 3.35 & 3.43 & 3.89 & 3.36 & 4.06 & & \\
\hline & $\mathrm{C} 3$ & & & 3.33 & 3.88 & 3.40 & 3.66 & & & & \\
\hline
\end{tabular}




\section{Methanol}

With van der Waals corrections

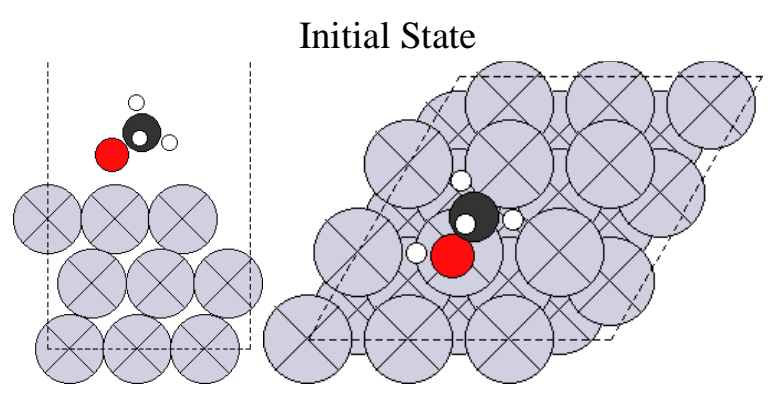

Transition State for Translation

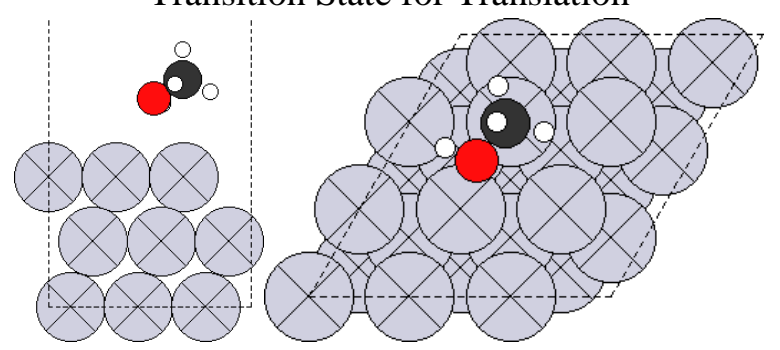

Transition State for Rotation

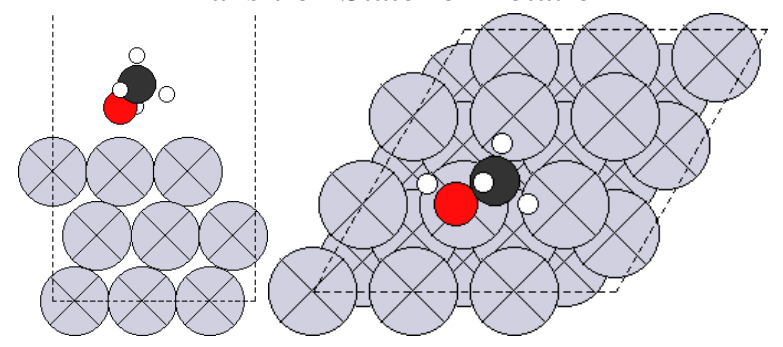

Without van der Waals corrections

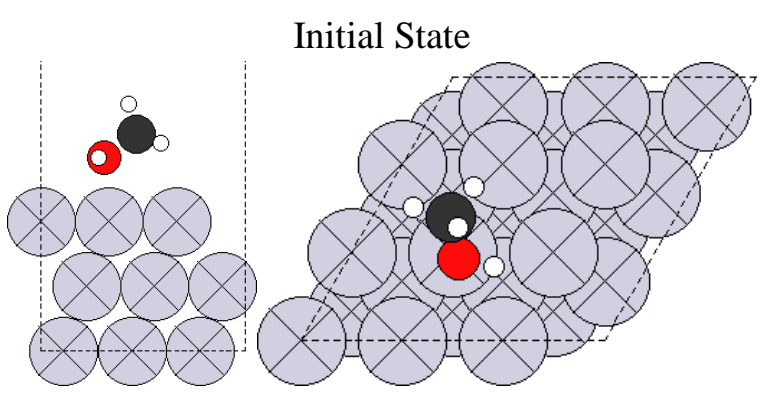

Transition State for Translation

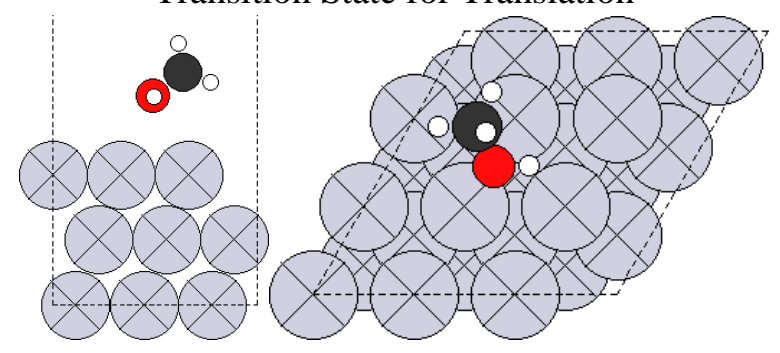

Transition State for Rotation

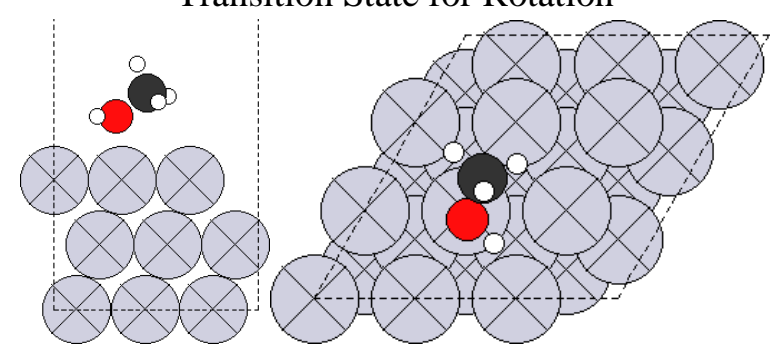




\section{Propane $\left(\mathrm{C}_{2}\right)$}

With van der Waals corrections

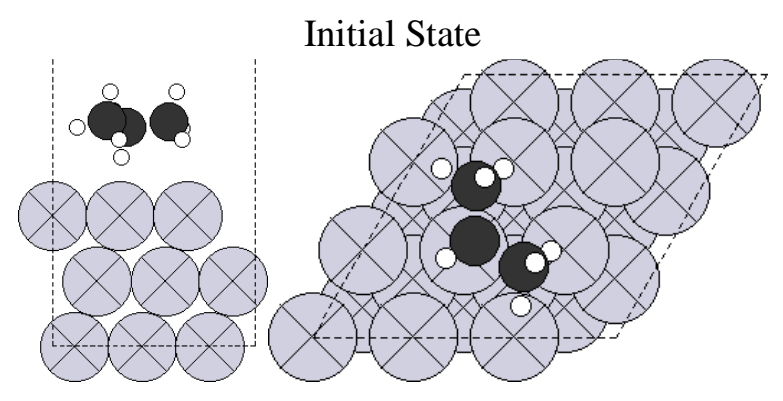

Transition State for Translation

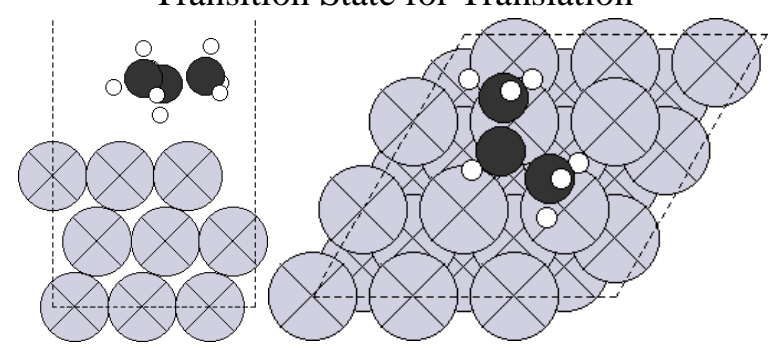

Transition State for Rotation

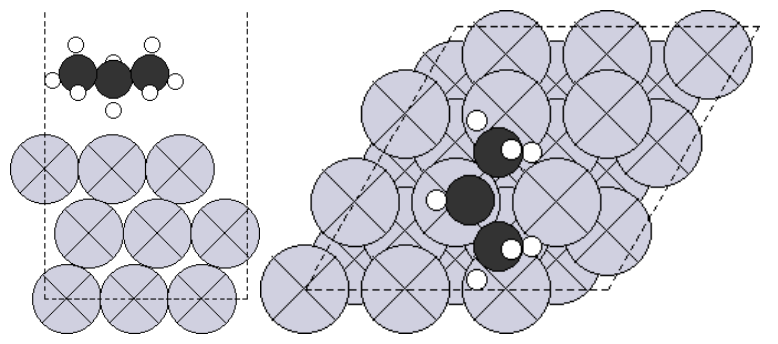

Without van der Waals corrections

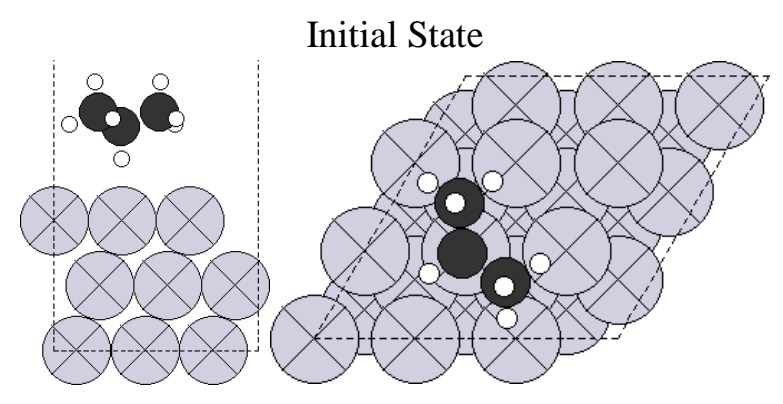

Transition State for Translation

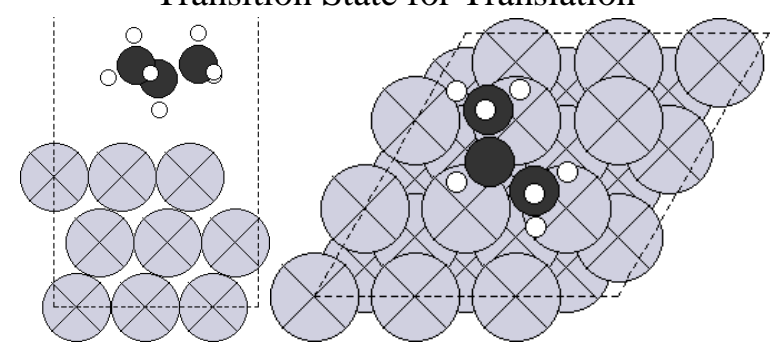

Transition State for Rotation

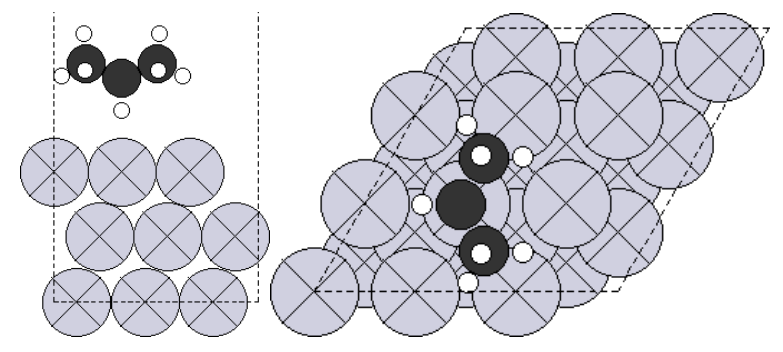




\section{Propane $\left(\mathrm{C}_{1}\right)$}

With van der Waals corrections

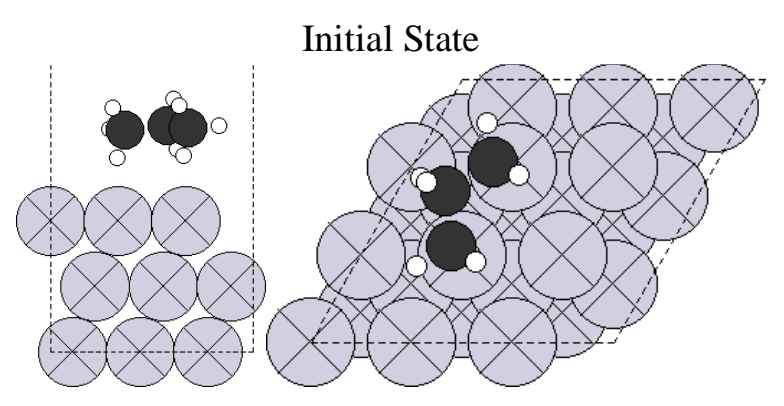

Transition State for Translation

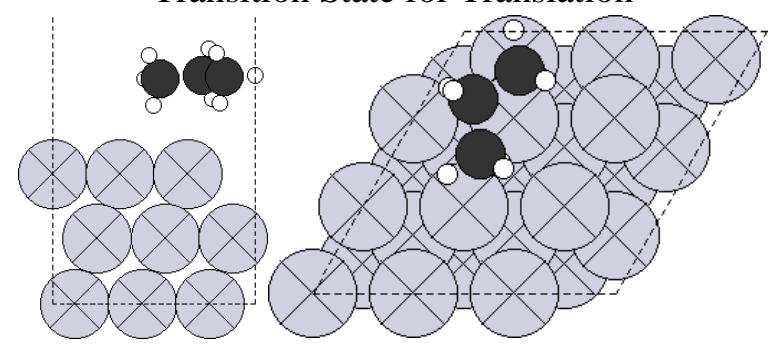

Transition State for Rotation

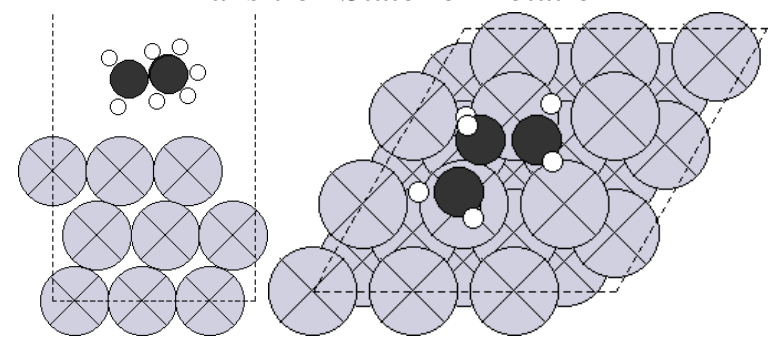

Without van der Waals corrections

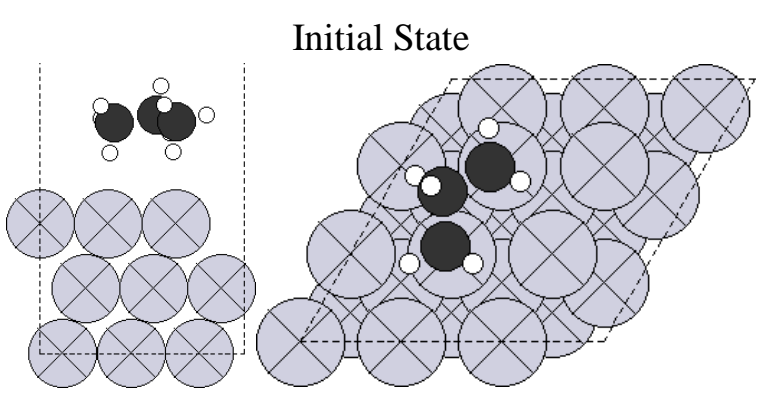

Transition State for Translation

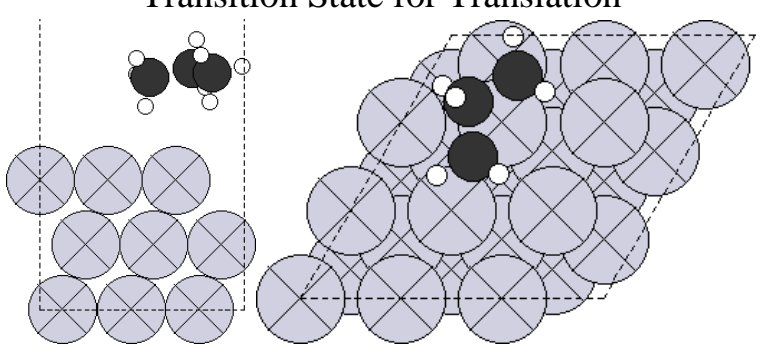

Transition State for Rotation

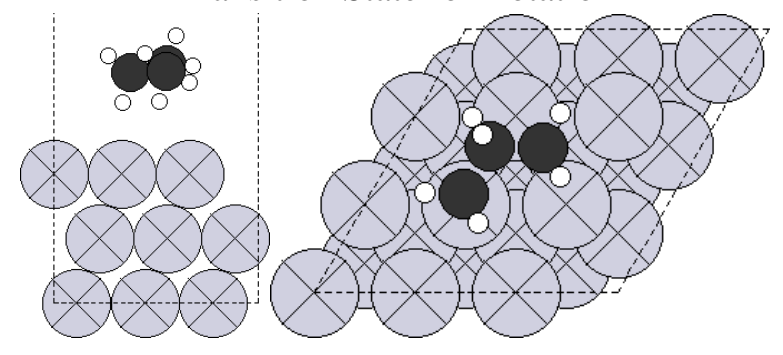




\section{Ethane}

With van der Waals corrections

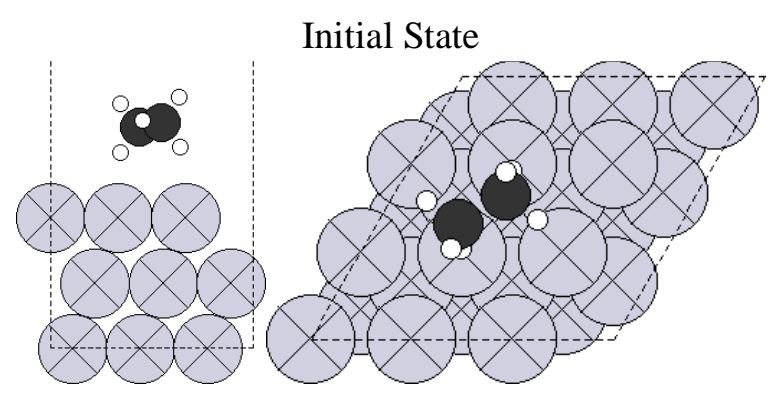

Transition State for Translation

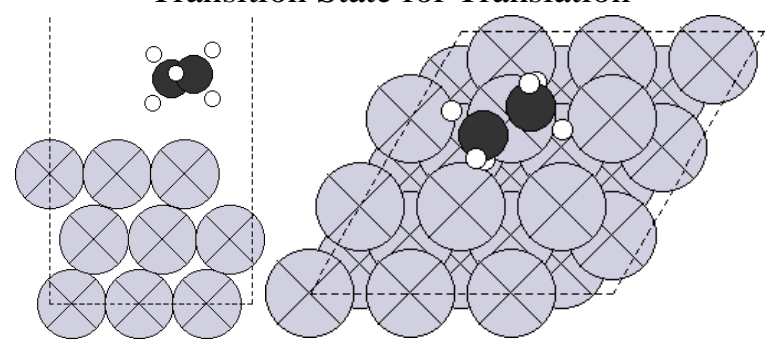

Transition State for Rotation

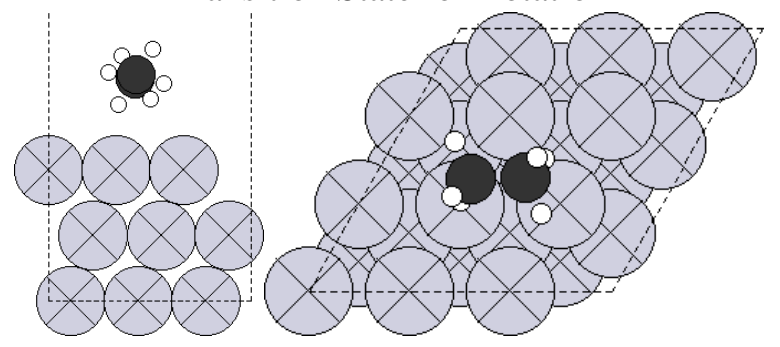

Without van der Waals corrections

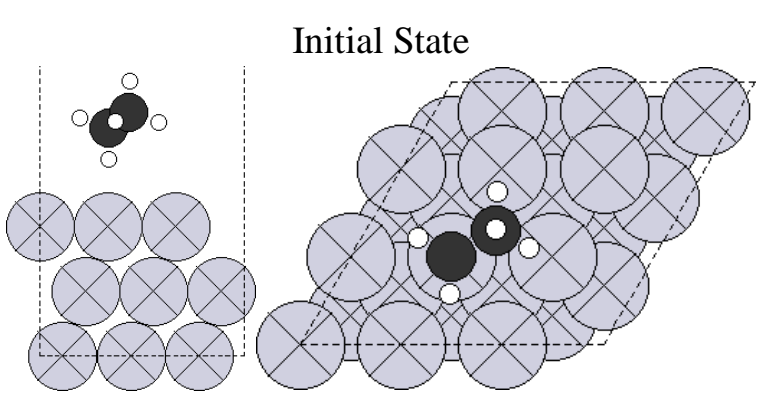

Transition State for Translation

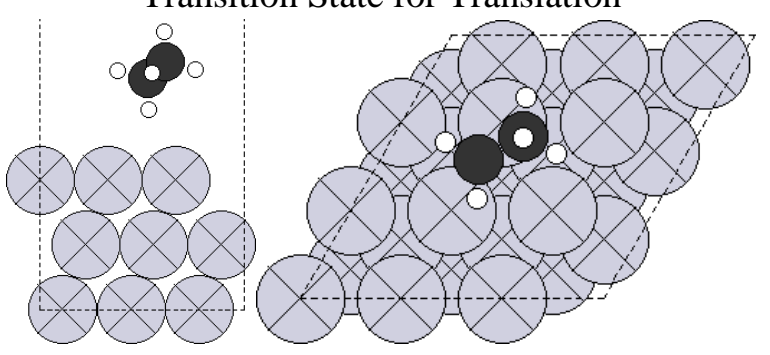

Transition State for Rotation

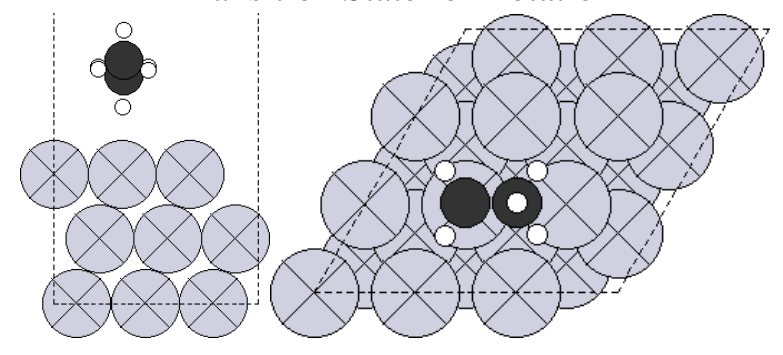




\section{Methane}

With van der Waals corrections

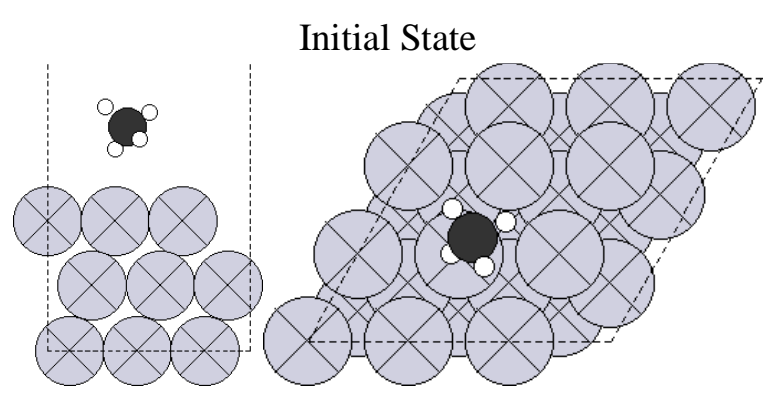

Transition State for Translation

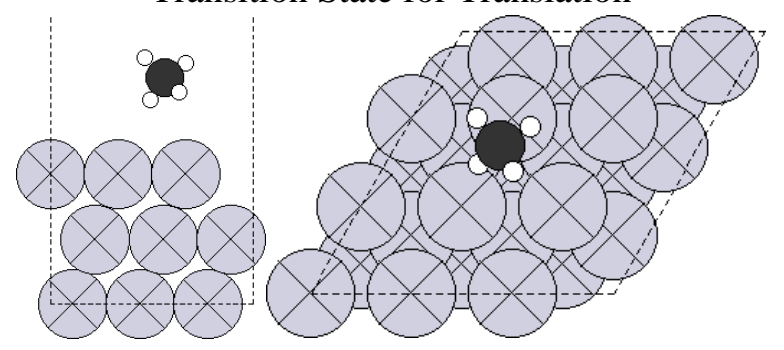

Transition State for Rotation

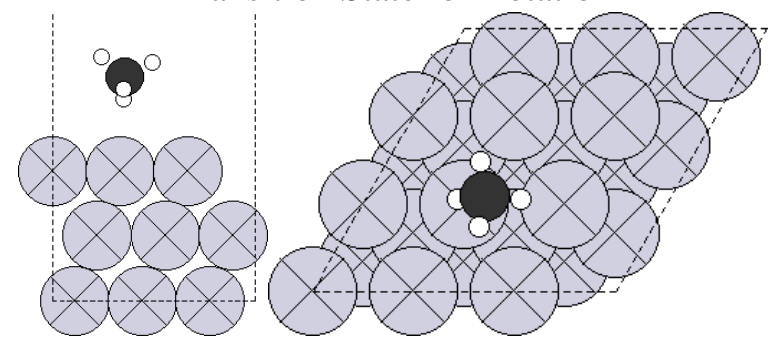

Without van der Waals corrections

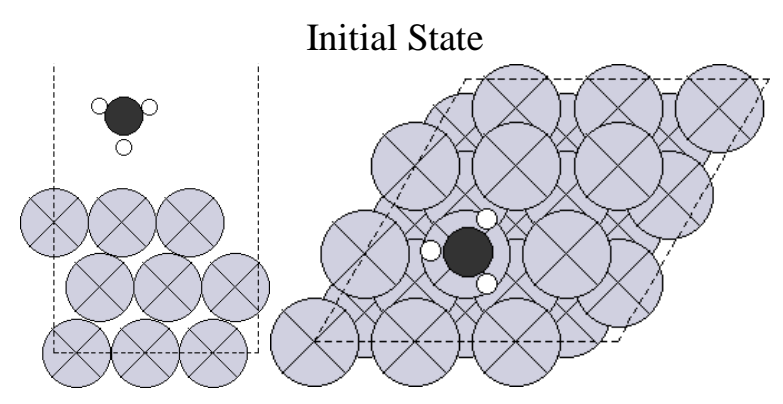

Transition State for Translation

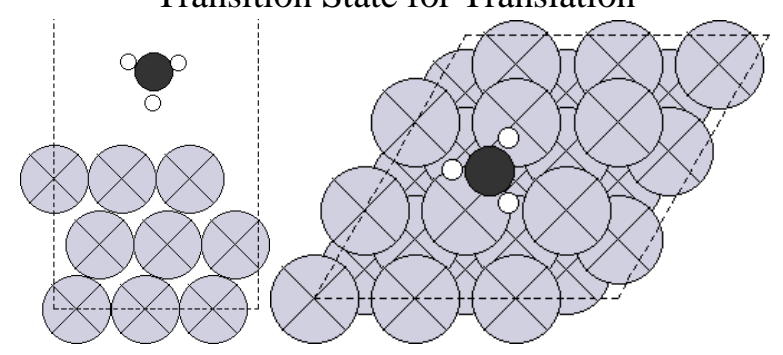

Transition State for Rotation

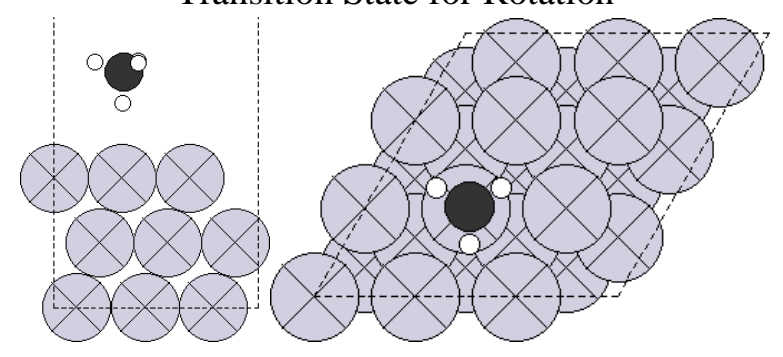

